\title{
TIMING JITTER MEASUREMENTS AT THE SLC ELECTRON SOLRCE'
}

\author{
J. SCDJA, M. J. BROWNE. AND J. E. CLESDENIX
}

Stanford Linear Accelerator Center. Stanford L'niversity, Stanford. Califormia 94jog

\section{ABSTRACT}

The SLC thermonic gun and electron source produce a beam of up to $15 \times 10^{10}:-$ in a single $S$. band bunch. A lio kel: 2 ns FWHM pulse on! of the gun is compressed by means of twa subharmonir bunchre cavities followed by an S-band buncher and a standard SL AC accelerating section. Ceramic gaps in the beam pipe at the output of the gun allow a measure of the beam intensity and tining. A measurement at these gaps of the timing jitter, with a resolution of $<10 \mathrm{ps}$, is described.

\section{INTRODUCTION}

The SLC thermionic electron source (CJD) and injectoi (Sectors zero and one) are fully described elsewhere. 'The tim. ing jitter measurements described here were done at CID using a ceramic gap monitor located in the beam pipe at the $200 \mathrm{kel}$ (max) point (Gun Gap) and a gap at the $40 \mathrm{MeV}$ point (Accelcrator $\mathrm{Gap}$ ). A sehematic of CID is shown in Fig. 1. Briefly: consists of a dispenser-type cathode thermionic gun. a pair of 16 th subharmonic buncher cavities, an $\mathbf{S - b a n d}$ buncher, and a $3 \mathrm{~m}$ SLAC accelerating section. The gun is currently operated at a DC voltage of $155 \mathrm{keV}$ and generates $2-3 \mathrm{~ns}$ FWHM electron pulses. A representative signal of sucb a gun pulse, observed at the Gun Gap monitor prjor to any bunching, is shown in Fig, 2. Typically, $60 \%$ of the gun pulse charge is captured and bunched. The fully bunched beam emerges at the end of the CID accelerating section with an energr of about $40 \mathrm{Mel}$. compressed into a bunch length of about $25^{\circ}$ of S-band. A representative signal of such a single, relativistic $S$-band bunch beam at the 40 HeV Accelerator Gap is shown in Fig. 3.

\section{BEAM TIMING STABILITY}

The reason beam timing jitter js of concern at the SLC is that any timing change of the beam relative to the accelerat. ing S-band phase results in a beam energy change. Thus, beam

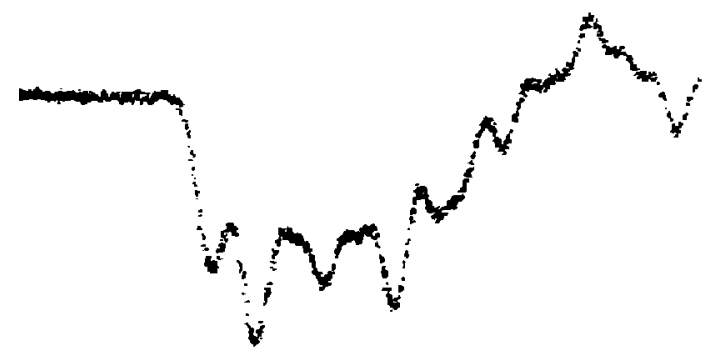

Fig. 2. The full, unbunched Gun Gan mantor signal veutd with $69 \mathrm{~dB}$ attenuation on a digitizer samplung scopr. (Ciun Gap calibrulion es $101 \%$ A. S Scope st ngs: 500 pos/du and $10 \mathrm{Al} / \mathrm{da}$.

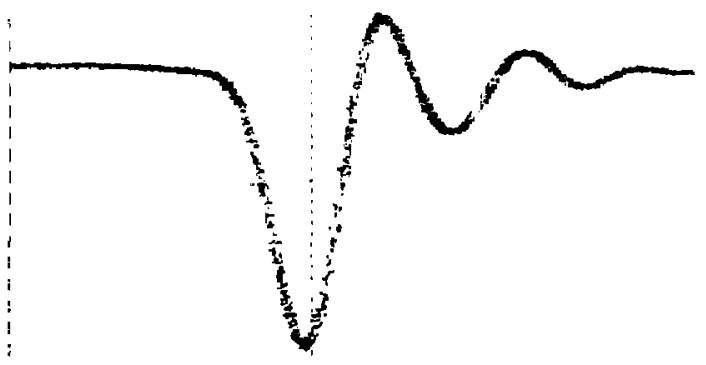

Fig. 9. The single S-band bunch Accelcrotor Gap monvor sig. nol viewed with 56 dB attenualion an a digitizer sompling scope. (Accelerator Gap calibration is $10 \mathrm{~V} / \mathrm{A}$.) Scope setfings: $200 \mathrm{ps} / \mathrm{dic}$ and $20 \mathrm{Ml} / \mathrm{dit}$.

SLAC-PUB- -4938

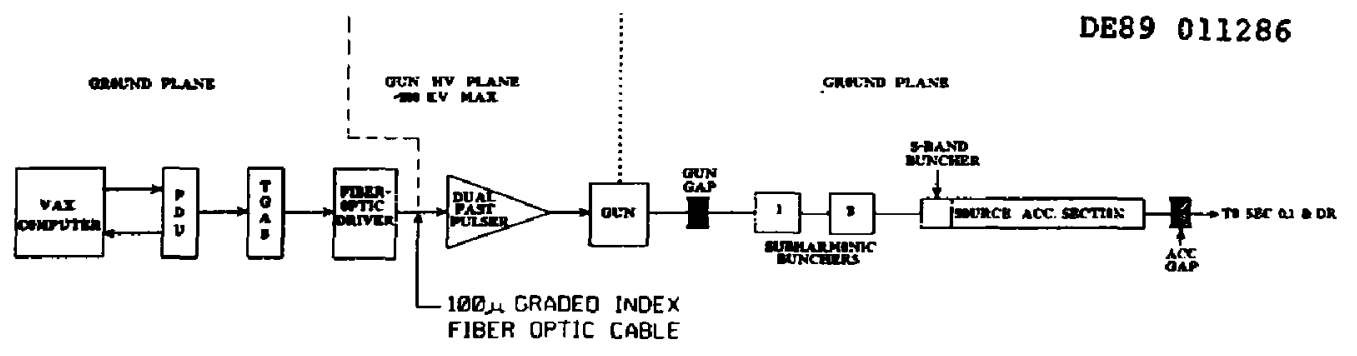

Fig. 1. Schematic drawing of the SLC electron source (CID) with assacialed gun trigger/pulser sysiem. Abbreviations used are PDL for pulsed delay unit, TGAS for trigger gate and synchronization, and DR for damping ring.

'Work supported by Department of Energy contracts DE-AC03-76SF90098 and DE-AC.03-76SF0051.5.

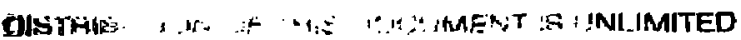


timing stability is required to avoid excessive beam energy jitter or drifts. This issue has been discussed in detail elsewhere? Since CID provides an elertron beam which-upon further acceleration to an energy of $1.2 \mathrm{GeV}$ in Sectors 0 and 1 of $t$. SLC injector-is transported to the emitlance damping ring. the timing stability rer, uired for the SLC electron source is determined by the $\pm 1 \%$ energy acceptance of the electron damp. ing ring.

An energy change of $1 \%$ cas be produced when the liming of the accelerated, single bunch beam changes by as little as $3 \mathrm{ps}^{2}$. The timing jitter dounstream of the gun, however, is redured by the bunching process roughly equivalent to the beam compression ratio acbieved. As stated in Ref. 2, this ratio is about 75 , but haries depending on the tuning conditions of the CID bunching system.

A previous measurement ${ }^{2}$ showed an upper limit on the gun timung jitter measured at the Gun Gap of $\sigma=20 \mathrm{ps}$, limited by the resolution capability of the measuring instrumentation (a Tektronix 7834 Sampling Scope). It further showed that thr beam energy jitter observed at as analyzing station at the 200 MeV point was about one tenth the energy acceptance of the damping ring. and was due mainly to jitter is the phase of the RF accelerating field.

\section{NEW TIMING JITER MEASUREMENT}

Since Ref. 2 was written. a new module, the Trigger Gate and Syrichronization (TGAS) module. ${ }^{3}$ was installed in the CID Gun pulser system (see Fig. 1), allowing gating of the gun trigger, as well as continuous timing adjustment of the trigger in severa' picosecond steps. The timing adjustment is achieved by syuchronizing the gun trigger to an $R F$ signal $(178.5 \mathrm{MHz}$. i.e.. the 16th subharmonic of the S-band RF) whose phase is then varied to achieve the desired gun timing. The timing jit. ter measurement presented bere is the first that has been done since this trigger system modification, and it was done with a newily available digitizer sampling scope (HP5120T Digitizing Oscilloscope). This scope has a resolution of about $10 \mathrm{ps}$. better than the instrument in Ref. 2 . In addition, the jitter was measured both on the unbuached beam at the output of the gun. i.e., at the Gun Gap monitor, as well as on the single $S$-band bunch beam at the output of the CID $3 \mathrm{~m}$ accelerating section-i.e., at the Accelerator Gap monitor.

The measurement at both monitors was done by expanding the leading edge of the beam gap monitor signal and collecting one bundred samples of timing values within a small voltage window of the signal. The jitter at the Gun Gap was measured to have a $\sigma=12.1$ ps, as shown in Fig. A.; the jitter at the Accelerator Gap was measured to have a $\sigma=8.7 \mathrm{ps}$, as shourn in Fig. 5. The Accelerator Gap measurement is almost certainly a measurement of the scope time resolution. Subtracting in quadrature tbe measured resolution from the Gun Gap jitter results in $\sigma=8.4 \mathrm{ps}$.

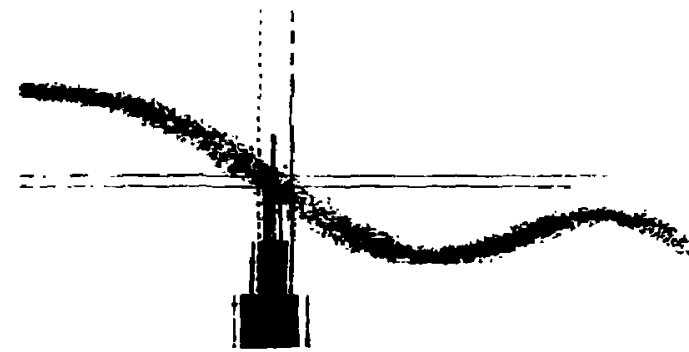

Fig. 1. Gun Gap signal leading edge of Fig. 2, expondid for thm jitter measuriment. Scope sethngs: $50 \mathrm{ps} / \mathrm{du}$ and $10 \mathrm{l} .1 \mathrm{i} / \mathrm{dul}$. Toming jitter sigma $=12.1 \mathrm{ps}$.

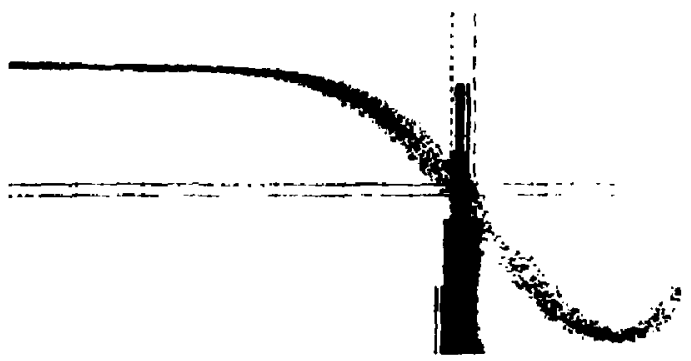

Fig. 5. Accelerator Gap leading edge of Fig. S. expanded for lime jitter meosurement. Scope settings: $50 \mathrm{ps} / \mathrm{dir}$ and $10 \mathrm{l} 1 \mathrm{1} \% \mathrm{dul}$. Timing jiller sigma $=8.7$ ps.

\section{CONCLUSION}

The timing jitter of the SLC beam at the elcriron source now has a measured upper limit of $\sigma \leq 8.4 \mathrm{ps}$ al the gun out pul. This timing stability falls well within the stability requiremeuts for injection into the SLC emittance-damping ring.

\section{REFERENCES}

1. J. E. Clendenin, S. D. Ecklund. M. B. James et al.. Prac. of the 1984 Linear Accelemtor Conference. C51-84-1) (19S1). p. 457; and J. C. Sheppard, "Commissioning of the S1C Injector," Proc of the 1987 IEEE Particle Accele mator Conf. Washington, D. C. (1987), p. 43.

2. J. E. Clendenin, M. J. Browne, R. A. Gearhart ef ol., "Timing Stabilization for the SLC Electron Source," Proc. of the 1987 IEEE Particle Acoelerator Conf., Washington, D. C. (1987), P. 369.

3. SLC Hardware Reference Masual, internal SLAC Document.

\section{DISCLAIMER}

This report was prepared as an scoount of work sponsored by an agency of the United States Government. Neither the United Stales Government nor any agency thereof, nor any of their employeen, makes any warranty, express or implied. or assumes any legal liability or responsibiliny for the mor utacy, completeness, of usefulness of any information, upparatus, product, or process disclosed, or represents that its use would not infringe privately owned rights. Reference tereio to any specific commercial product, process, or service by trade name, trademark, manufacturer, or otherwise does not mecessarily canstitute or imply its endorsement, recommendation, of favoring by the Uaited States Governument or any agency theseor. The views and opinions of authors expressed berein do not necessarily state or reflect those of the United States Government or any agency theroor. 